\section{artelogie}

\section{Artelogie}

Recherche sur les arts, le patrimoine et la littérature de l'Amérique latine

10 | 2017

Après le paysage : l'art, l'inscription et la représentation de la nature en Amérique latine aujourd'hui

\title{
Panorama general
}

Jacques Leenhardt, Maria José Marcondes y Catalina Valdés

\section{(2) OpenEdition}

Journals

Edición electrónica

URL: http://journals.openedition.org/artelogie/1263

DOI: $10.4000 /$ artelogie. 1263

ISSN: 2115-6395

Editor

Association ESCAL

Referencia electrónica

Jacques Leenhardt, Maria José Marcondes y Catalina Valdés, «Panorama general », Artelogie [En línea], 10 | 2017, Publicado el 05 abril 2017, consultado el 24 septiembre 2020. URL : http://

journals.openedition.org/artelogie/1263; DOI : https://doi.org/10.4000/artelogie.1263

Este documento fue generado automáticamente el 24 septiembre 2020.

Association ESCAL 


\title{
Panorama general
}

\author{
Jacques Leenhardt, Maria José Marcondes y Catalina Valdés
}

1 Revista Artelogie publica su décimo número con una serie de novedades editoriales que nos complace compartir con nuestros lectores. A contar de este número, la revista estará alojada en Revues.org, plataforma de revistas de ciencias humanas y sociales de Francia que forma parte del portal OpenEdition. Asimismo, con este décimo número inauguramos una colaboración con la revista Critique d'art, publicación de los Archives de la critique d'art de Rennes, Francia. Por medio de esta colaboración, las reseñas de libros que incluimos en este y en los próximos números serán traducidas al francés y publicadas también en dicha revista. Tanto la integración a Revues.org como la colaboración con Critique d'art representan un reconocimiento al trabajo académico y editorial que hemos impulsado desde Artelogie en estos años, inscribiendo a nuestra revista en una red de publicaciones digitales que ampliará su difusión y otorgará a los estudios de historia del arte y cultura latinoamericana una visibilidad mayor en el ámbito académico internacional y francés en particular.

2 Este nuevo número se propone como plataforma poética y crítica de una cartografía de artistas, imágenes, ideas - frente a la representación y las inscripciones de la naturaleza en el arte de América Latina. Con este objetivo hemos llamado a investigadores, artistas y gestores de diferentes disciplinas vinculadas al paisaje de la producción para presentar sus colaboraciones.

3 Este número de Revista Artelogie parte de la idea que las representaciones artísticas de la naturaleza en América Latina dan cuenta de una construcción cultural matizada por los procesos de colonización europea del continente desde el siglo XV y por su posterior formalización como estados modernos desde comienzos del XIX. Las imágenes de lugares naturales y culturales producidas en este período representan la experiencia directa o diferida de artistas -mayoritariamente extranjeros- que contribuyeron a crear un imaginario determinado por lo exótico, lo exuberante, lo sublime o lo pintoresco. La percepción de la naturaleza toma forma a partir de modelos estéticos de tradición europea, entrando en tensión, en diálogo o en combinación con las culturas locales. Así, conforman patrones epistemológicos (estéticos y científicos) de apropiación de la realidad particulares a la región. 
Desde una posición crítica postcolonial han surgido en los últimos años obras de arte y estudios de reinscripción histórica en los que se revela la función colonizante que pueden cumplir las representaciones visuales de la naturaleza americana producidas por (y en principio, también, para) la mirada europea. Dicha revisión crítica ha detectado los dislocamientos e interferencias estéticas que el encuentro entre Europa y América desencadenó en ambos sentidos, transformando de un modo determinante la relación de los sujetos con el entorno natural.

5 Para este marco renovado de estudios sobre la historia del arte latinoamericano, la pintura de paisaje decimonónica se ha vuelto uno de los objetos que permite lo mejor revisar las funciones de la imagen en los procesos de formación de las identidades nacionales. Esta perspectiva no pierde de vista las cuestiones contingentes que el paisaje coloca en tanto género pictórico y manifestación de un proceso más amplio, que implica el ingreso de imaginarios y territorios a los cánones de la modernidad. De esta manera, se trata de una mirada crítica que reconoce la diversidad de modos con que la pintura de paisaje representa lugares, ocupando frecuentemente un papel notable en los procesos de formación de identidades nacionales, al mismo tiempo que levanta cuestiones contingentes, visibles desde una visión contemporánea y crítica.

6 Hacia el fin del siglo XIX y comienzos del XX, escritores y artistas locales se aproximaron al paisaje experimentando nuevas figuras retóricas, formas y estilos, recurriendo a la abstracción y a materialidades y técnicas no convencionales. Por medio de imágenes de sesgo político, reafirmaron una los bordes de una identidad local desde una visión renovada de nociones como nacionalismo, indigenismo o latinoamericanismo. En ellas, la naturaleza parece ocupar la función de materia prima, garante de la utopía modernizadora.

7 Hoy, ante la contingencia de una naturaleza amenazada -y amenazante-, cabe indagar sobre la reubicación de la condición humana en el ámbito de lo natural, así como en la relativización de la oposición global/local; dos distinciones que sustentaban el orden moderno. Tanto el relato del cambio climático -cuyas causas y efectos se expanden a nivel mundial- como el desarrollo reciente de teorías sociales y científicas que observan la desaparición de los límites entre naturaleza y cultura, exigen del arte contemporáneo latinoamericano (y de las lecturas contemporáneas del arte) una revisión de sus propias condiciones geopolíticas, lo que implica una reconceptualización de la noción misma de paisaje.

8 El número que presentamos aquí ofrece múltiples entradas a estas problemáticas sin circunscribirse a ningún límite geopolítico ni temporal en particular, así como tampoco corresponden a una misma disciplina o práctica cultural. Los temas que se abordan en los artículos, entrevistas, notas de exposición y reseñas de libros aquí reunidos, requieren, necesariamente, la amplitud de una mirada transdisciplinaria. Al tiempo que los textos se apoyan en análisis de casos particulares, sus autores establecen relaciones que explicitan el alcance global de los fenómenos que abordan.

9 Reconociendo en los artículos una perspectiva social que les es transversal, los hemos organizado de modo cronológico de tal modo que puedan evocar un cierto desarrollo histórico de las representaciones de la naturaleza. Comenzando por las construcciones pictóricas del paisaje, los artículos de Carla Hermann y María Beatriz H. Carrión abordan obras y artistas viajeros, que a medida que transitan, van adquiriendo nuevos sentidos. El artículo de Jens Andermann integra esta misma dimensión dinámica al estilo arquitectónico. En los tres casos, estos autores explicitan los alcances ideológicos 
de manifestaciones que convencionalmente habían sido inscritas como representativas $\mathrm{y}$ oficiales, fuera de una nación como de una particular localidad.

Geógrafa e historiadora del arte brasileño Carla Herman estudia los panoramas de la ciudad de Río de Janeiro hechos por el artista francés Félix Taunay y por el británico Robert Burford, y que fueron expuestos en París y Londres, respectivamente. El autor analiza las diferentes estrategias de estos artistas en la representación de la naturaleza del paisaje construido y expuesto en Europa, buscando entender las estrategias y las dinámicas de la visión del otro en un doble sentido que implica la condición de artistas extranjeros pero también de los espacios de exposición.

La historiadora del arte ecuatoriana, María Beatriz Haro, analiza en el artículo "Seduciendo al mundo con paisajes: las imágenes de El Ecuador en Chicago" el tema de la construcción cultural de las identidades y de las nacionalidades en las representaciones de la naturaleza. Así, analizando la imagen del paisaje costero ecuatoriano en el libro $\mathrm{El}$ Ecuador en Chicago, obra conmemorativa por su participación en la Exposición de Chicago en 1893; concluyendo que la construcción de estos paisajes buscó construir un país moderno y una "naturaleza artificializada", que se apartó de las representaciones pictóricas del Ecuador ligadas a la construcción pictórica de lo sublime natural propias al arte de mediados del siglo XIX.

12 Por su parte, el ensayista alemán, experto en estudios culturales latinoamericanos Jens Andermann, analiza la construcción social del paisaje de la Patagonia Argentina en el texto "Estilo austral : paisaje, arquitectura y regionalismo nacionalizador en el Parque Nacional Nahuel Huapi (1934-1943)". A partir del estudio de la arquitectura y de la configuración del paisaje en el desarrollo del turismo de la primera mitad del siglo XX, Andermann detecta las dinámicas colonialistes del control y de la posesión de territorios y revela las contradicciones de un orden moderno que se instala con diversas formas, pero que se impone también gracias a las leyes del mercado, por la privatización de las costumbres y del gusto en las regiones distantes de la ciudad.

Los estudios que abordan manifestaciones contemporáneas permiten reconocer los gestos de una crítica postcolonial en los términos de una estética e incluso, de una ética, que atraviesa las producciones literarias, visuales, curatoriales para constituirse en una experiencia de mundo -natural y cultural y en todos los casos, político. Así, el artículo de la escritora y traductora argentina Azucena Galettini propone una reflexión en torno a las evocaciones poéticas de la naturaleza caribeña en las obras de autores que escriben en inglés, aproximándose a una imaginación paisajística desde las experiencias de desarraigo y extranjería. Se desprenden de su análisis las operaciones de desarticulación de la mirada exotizante e idealizante de la producción literaria precedente (aquella que ha sido considerada nacional o más auténtica) y de sus correspondencias con dinámicas de explotación humana y no humana del territorio como marcas de esta poética caribeña contemporánea en lengua inglesa.

En el mismo sentido, el investigador y crítico cultural brasileño Fábio Zucker escribe sobre la obra de Daniel Steegmann Mangrané, artista español que vive en Brasil. Zucker vincula sus sutiles intervenciones e instalaciones con modos de ver y relacionarse con el mundo de los indios del Amazonas, guiándose por observaciones antropológicas. La interdisciplinariedad que estaba en la base de la convocatoria de este número se materializa en este artículo.

El dossier de artículos se cierra con el texto de la historiadora del arte mexicana Aracelli Barbosa Sánchez, "Representación del paisaje americano desde la perspectiva 
de la sustentabilidad", en el cual se traza una cartografía de artistas, investigadores y gestores de paisaje en América Latina, atentos a la conciencia ambiental surgida del cambio climático, los llamados desastres ambientales o para decirlo de otra manera, el proceso antrópico que sufre nuestro tiempo.

Aprovechando la coincidencia de eventos que ocurrieron simultáneamente con el desarrollo de ese número, el equipo editorial recibió una serie de colaboraciones en formato de entrevistas vídeos, conversaciones escritas, comentarios de exposiciones y publicaciones críticas. La exposición: L'Atelier tropical de Jean-Baptiste Debret, peintres, écrivains et savants français au Brésil, 1816-1850, celebra el bicentenario de la Misión Artística Francesa al Brasil. Exibida en el Museo Castro Maya Río de Janeiro, y en la Maison de l'Amérique Latine en París, la exposición es comentada por una entrevista con el comisario y sociólogo del arte francés Jacques Leenhardt. El vídeo de la exposición y las entrevistas son complementarias a una reseña sobre la reedición de trabajo JeanBaptiste Debret, Voyage pittoresque et historique au Brésil con un prefacio del mismo Leenhardt, preparada por el curador e historiador del arte carioca, Raphael Fonseca.

La entrevista realizada por el historiador de arte Marta Penhos al pintor argentino Leonel Luna con objeto de la exposición Paisajes Americanos (curada por Cecília Cavanagh del Pabellón de las Artes de la Universidad Católica de Buenos Aires, 2016) aborda el paisaje heterotópico, lo pintoresco y lo sublime revisado por la visualidad contemporánea, especialmente en el análisis de la obra Límites de que articula el pasado con el presente en el texto de Marta Penhos, con la historia social del país. En la entrevista, la autora analiza el tema del paisaje para el artista, como una idea que se transforma continuamente y la adjetivación de Paisajes Americanos, tales que la relación entre la geografía, el territorio y los lugares.

El historiador del arte brasileño Renato Menezes entrevista al historiador Luis César Marques, especialista del arte y la cultura del Renacimiento que se ha dedicado de lleno al estudio de la reciente historia del capitalismo global y las condiciones de la crisis ambiental, volcando todo su arsenal como investigador y ensayista desarrollar una escritura política y urgente.

19 Dos revisiones de exposiciones reflexionan sobre las propuestas artísticas actuales ante el binomio naturaleza / cultura. El curador y crítico brasilero Gabriel Bogossian analiza la exposición La caída del cielo (2015) y Resistencias contemporáneas (2016) curadas por Moacir dos Anjos, en el documento de trabajo "Um museu ausente: curadoria contemporânea e ativismo indigenista, como respuesta a la interrogante que este dossier plantea en torno a la relación entre las prácticas artísticas, antropológicas y / o históricas y la naturaleza y la cultura en las sociedades indígenas de América Latina.

20 La actualidad de los temas abordados en este dossier dialoga con obras de poéticas visuales en las que los paisajes heterotópicos, lo pintoresco y lo sublime son revisitadas por la producción contemporánea, tal como pone de relieve María Teresa Márquez, ensayista chilena, frente a la exposición Hidropoética, expediciones Antárticas, a cargo de Ricardo Mancillas Garay, (2016/2017) en el Museo de Arte contemporáneo de Santiago (Chile).

21 Por último, dos reseñas abordan publicaciones recientes que amplían el campo de las relaciones entre el arte, la naturaleza y la cultura, a partir de perspectivas históricas, iconográficas y antropológicas. Escrita por la historiadora de arte chilena Catalina Valdés, la primera recensión comenta el catálogo de la exposición "Picturing the Americas. Landscape painting from Tierra del Fuego to the Artics" (2015); y la segunda, de 
Fábio Zucker, presenta el libro de Déborah Danowski y Eduardo Viveiros de Castro Há um mundo por vir? Ensaios sobre medos e fins apresenta uma reflexão dos autores sobre o pensamento ameríndio (2014) - obra que inspira los distintos argumentos planteados por los autores que participan en este número. Teniendo en cuenta la contingencia del campo artístico actual, la profesor y crítica de arte brasileña Maria José Marcondes presenta un análisis de los fundamentos conceptuales de la curaduría de la 32 $2^{\text {a }}$ Bienal de São Paulo (2016), acercándose a las obras de algunos autores Ibero -americanos desde una perspectiva cultural postcolonialista, reconociendo en algunas obras presentes en esta edición de la Bienal, la activación de una "epistemología del Sur", entendida como el rescate de las culturas tradicionales y la proposición de una poética visual sobre el tema de la emergencia ecológica.

\section{AUTORES}

JACQUES LEENHARDT

EHESS

MARIA JOSÉ MARCONDES

Instituto de Artes, UNICAMP

CATALINA VALDÉS

Universidad de Chile 